\title{
Chapter 26 \\ Climate Change, Ecological Stress \\ and Livelihood Choices in Indian \\ Sundarban
}

\author{
Santadas Ghosh and Sreejit Roy
}

\section{Key Messages}

- The younger generation from Indian Sundarban delta is mostly opting for migrant labour jobs outside the region.

- Individual educational attainment is found to have an inverse relationship with activities like fish and crab collection. Education enables the local youth to gather more information and to move outward.

- A policy of incentivizing and facilitating basic education among youth in these remote rural locations may increase their livelihood resilience and help in reducing ecological stress.

\footnotetext{
Disclaimer: The presentation of material and details in maps used in this book does not imply the expression of any opinion whatsoever on the part of the Publisher or Author concerning the legal status of any country, area or territory or of its authorities, or concerning the delimitation of its borders. The depiction and use of boundaries, geographic names and related data shown on maps and included in lists, tables, documents, and databases in this book are not warranted to be error free nor do they necessarily imply official endorsement or acceptance by the Publisher, Editor(s) or Author(s).
}

\section{S. Ghosh (凶)}

Department of Economics and Politics, Visva-Bharati University, Bolpur, West Bengal, India e-mail: santadas_ghosh@yahoo.co.in

\section{S. Roy}

Department of Economics and Politics, Visva-Bharati University, Bolpur, West Bengal, India e-mail: sroy106@gmail.com 


\subsection{Introduction}

\subsubsection{Sundarban: Geography, Ecology and People}

Spread over India and Bangladesh, the Sundarban is the largest single mangrove forest in the world, an ecological hotspot and a UNESCO World Heritage Site for its biodiversity significance. The region is a tidal delta, and its islands are yet to attain matured heights. On the Indian side, out of a total of 102 islands, 48 falls within the Sundarban Reserve Forest (SRF) that is home to the famous Royal Bengal Tiger. The remaining 54 islands are inhabited by over 4.5 million people (WWF, n.d.). The SRF and the settlements are on two mutually exclusive sets of islands. Human settlements were made possible only by earthen embankments all around the islands, which sustain freshwater agriculture amidst surrounding saline waters. In the Indian part, a large area outside the SRF is declared in 1989 as the Sundarban Biosphere Reserve which covers a considerable area outside the deltaic islands. The SRF lies in the eastern corner of India bordering Bangladesh while the populated islands are located along the western periphery of the delta.

This mangrove ecosystem is highly productive in terms of forest biomass and nutrient contribution, especially through detritus-based food webs that support rich biodiversity in this estuarine delta. It is a nursery ground for many kinds of fish and other species and is responsible for maintaining the fish stock and aquatic diversity for a vast area in the northern Indian Ocean (Neogi et al., 2017).

People have started settlements on these erstwhile mangrove-dominated islands within the last two centuries. As population expanded over time, the shortage of productive land led to the clearance of large areas of mangrove for agriculture and aquaculture. Studies have identified the changing salinity profile of the delta due to climate change as well as human intervention. It is, however, indicated that increasing glacial melt from the Himalayas might have decreased the salinity at the mouth of the Ganges in the eastern sector of Sundarban that lies in Bangladesh. At the same time, salinity has increased in the central sector, where the connections to the freshwater sources upriver have been ruptured due to heavy siltation and construction activities. The impact of such changes could be alarming for the ecosystem (Banerjee, 2013).

Sundarban's large human population is exposed to a new set of challenges posed by global climate change. Studies indicate that changes in river discharge, tides, temperature, rainfall and evaporation will affect the wetland nutrient variations, influencing the physiological and ecological processes and hence biodiversity and productivity of Sundarban mangroves. Hydrological changes in wetland ecosystems through increased salinity and cyclones will lower food security and increase human vulnerability to waterborne diseases (Neogi et al., 2017). The ripple effect of these changes will have multi-faceted adverse impacts on the nature-dependent livelihoods of nearby communities. Studies have concluded that elevated health risks, reduced land and labour productivity and increased exposure to storms, floods, droughts and other extreme events will make escape from poverty more difficult for the local communities (Dasgupta et al., 2020). 


\subsubsection{Climate Change Threats to Local Livelihood}

Research interest in this region picked up after climate change predictions identified this large coastal population, including those residing in the Bangladesh part of Sundarban, as one of the most vulnerable communities in the world. While the longterm vulnerability of this region is due to soil salinization and area loss from sea-level rise, the more immediate fallout is the predicted increase in cyclonic storm frequency in the Bay of Bengal. Using data on tropical cyclone frequency over the eastern coast of India from 1891 to 2013, a study concluded that there is indeed a trend of enhanced cyclogenesis during the months of May, October, November and December (Mishra, 2014). Another recent study analysed a geo-referenced panel database of cyclonic storm tracks in Bay of Bengal between 1877 and 2016. Considering the pattern of cyclone landfall history over the entire coastline of Bangladesh and that of the states of Odisha and West Bengal in India, the study found that the median location of cyclones has shifted eastward over time, with the highest-impact zones currently found in northern Odisha and in the Sundarban region of West Bengal in India (Dasgupta et al., 2020). The role that mangroves play by providing protection services has been well-documented by Das (2021, Chap. 17 of this volume) in the context of Odisha, India.

Studies have identified shifts in the distribution of aquatic species as well as in the timing of their reproduction (Neogi et al., 2017). Fisheries constitute an important source of livelihood for this poor remote island population. Studies conducted on the Bangladesh part of Sundarban show that aquatic salinization may have an especially negative impact on poor households in the region by 2050 . The estimates indicate that areas with poor populations that lose species are about six times more prevalent than areas gaining species (Dasgupta, 2017). Studies have also assessed respondents' risk perceptions of saline water inundation on such aquaculture through risk assessment tools. It was observed that respondents in low-lying areas of Sundarban considered cyclone and coastal flooding as extreme risk events (Chand et al., 2012).

Studies have also found that land and aquatic salinization would also affect the stock and spatial distribution of mangroves in Sundarban. Such changes are likely to affect the prospects for people's forest-based livelihoods. Salinity-induced mangrove migration is expected to have a strong regressive impact on the value of timber stocks because of the loss of the highest value timber species. In addition, the augmented potential for honey production is likely to increase conflicts between humans and wildlife in the region (Chowdhury et al., 2016; Dasgupta et al., 2017).

\subsubsection{Livelihood and Stress on Natural Resources}

Agriculture has always been the mainstay of people on these islands and provided local food security. Studies predict progressive salinization of water and soil will result in a decline in rice output by $15.6 \%$ in nine sub-districts of the Bangladesh part 
of Sundarban before 2050 (Dasgupta et al., 2018). Salinity ingression on farmland mostly occurs through storm surges and embankment collapse resulting from extreme weather events. The large-scale impact of such events was amply demonstrated by cyclone Aila in 2009 when it devastated large sections of protective embankments resulting in saltwater inundation of agricultural land and freshwater ponds on most islands, damaging crop productivity and agricultural patterns (Haldar \& Debnath, 2014).

River dynamics may have been accentuated in recent times as a result of climate change and sea-level rise, and there is regular river erosion and accretions in different parts of the delta. (Raha et al., 2012). But newly formed mudflats are invariably treated as government land and no one is allowed to settle there. As a result, the delta on the Indian side has a significant share of landless population and marginal farmers. Also, due to lack of irrigation facilities as well as basic infrastructure, agricultural practices are traditional and dependent on seasonal rainfall. People supplement their income by exploiting forest and surrounding aquatic resources (Mahadevia Ghimire \& Vikas, 2012). With decreasing land resources, there are more incursions inside the SRF area for fishing, crab catching and honey collection. Fishermen venture into forest creeks for better catch as those places are supposed to be richer in fish concentration. In the Indian part of Sundarban, around $20 \%$ of the islands' inhabitants are estimated to be surviving on fishing activities (Ghosh, 2017).

Going inside the reserve forest carries the risk of tiger attacks but the poor continue to do so for their livelihood. A study on the victims (both death and injury) between 1999 and 2014 estimates the risk of tiger attack in the range of $0.11-0.88$ for every 10,000 residents of the blocks surrounding SRF. The majority of the victims $(68 \%)$ were found to be male, aged between 30 and 50 years (Das, 2018).

Another form of natural resource extraction has also caused great harm to the aquatic resource stock. From the late 1980s, international markets started opening up for large-scale export of the locally available shrimp species usually referred as tiger shrimp (Penaeus monodon). Its juveniles were abundantly available in the local rivers and were in high demand by newly established inland shrimp farms. Collection of these juveniles started on a large scale and was a lucrative avenue to earn hard cash for the local poor. Over the next two decades, indiscriminate shrimp seed collection caused serious harm to other fish juveniles. This practice greatly contributed to the gradual decline in the fish populations in Sundarban (Gopal \& Chauhan, 2006; World Bank, 2014).

Estimation of yield, exploitation rate and maximum sustainable yield for major shell and finfish species in SRF has signalled overexploitation (Hoque Mozumder et al., 2018). The IUCN has already listed the status of a number of economically important fish species of Sundarban as 'threatened' (Hoq, 2007). Other studies have also identified the northern Bay of Bengal ecosystem as an exploited one as its fish stock is being steadily depleted under huge pressure from fishing (Dutta et al., 2017).

In recent times, the fall in relative price of shrimp-fry as well as government restrictions and environmental awareness programmes have led to some reduction in shrimp juvenile collection. Instead, collection of mud crabs (Scylla serrata) from the delta has greatly increased due to better realization of price in the international 
market (Nandi \& Pramanik, 2017). As crab is a keystone species for the mangrove ecosystem (Smith et al., 1991), intensification of its collection from the wild has also accentuated the anthropogenic stress on it.

Pressure on the Sundarban's ecosystem has also resulted from investments requiring clearing of mangrove forests. Studies identified that the Chakoria (Bangladesh) mangrove forest had completely disappeared between 1903 and 2010, primarily to make way for inland shrimp farms. Empirical evidence shows that such interventions resulted in significant livelihood loss for the local communities (Islam, 2014).

\subsubsection{Labour Outmigration}

Though settlements in Sundarban delta are relatively recent, increasing population and decreasing agricultural land coupled with dwindling fish stock is resulting in large labour outmigration in recent years. Increasing soil salinity associated with extreme weather events has decreased agricultural productivity, which in turn is fuelling such outmigration (Hajra \& Ghosh, 2018). In the aftermath of cyclone Aila (2009), which resulted in widespread and prolonged loss of agriculture in the delta, labour outmigration emerged as a predominant coping strategy for the local poor against their agricultural loss (Ghosh, 2013).

The extent of this phenomenon has been investigated in some studies both quantitatively and qualitatively. It is found that almost $75 \%$ of migrant labour travel inter-state and work in the western and southern Indian states. Almost 95\% of them are male and they mostly work as construction labour and come back to Sundarban in the monsoon period for paddy cultivation (Guha \& Roy, 2016; Mistri, 2013).

Much of the empirical literature on Sundarban hovers around climate change implications for local livelihood and its ecological health. The socio-economic profile of poor communities, those who exert direct anthropogenic stress on the ecosystem, is relatively less explored. A study conducted in Bangladesh found that the livelihood condition and education level of the Sundarban fishermen is very poor (Mondal et al., 2018). Similar inference is drawn for its Indian counterparts in another study (Mistri $\&$ Das, 2015). However, none of these studies is based on a reasonably large sample and does not detail the livelihood choices and their dynamics in this delta.

On the Indian side, there is a discernible shift in the livelihood mix of the Sundarban people in recent years, caused by population pressure and decreasing land and other natural resources. Migrant labour jobs are being adopted increasingly by the local youth, which is also facilitated by infrastructural development and easier communication through mobile connectivity. These livelihood dynamics have important implications for the local ecosystem as they may help in reducing anthropogenic stress. A study on the pattern of such spontaneous livelihood adjustments is crucial for devising supporting policies. Such a study is conspicuous by its absence in existing literature. 


\subsection{Objective, Study Area and Data}

This study intends to fill the research gap mentioned above. The data is generated from four different sets of household surveys in the region conducted during 2012, 2015, 2017 and 2019. Though the surveyed households were different across years, there is a large overlap in the Gram Panchayat areas that were covered. Altogether, the primary data consists of 2800 households having over 5500 adult earning members in them. It makes this study a rare one that uses such a large primary dataset from Sundarban and lends credence to the empirical evidence.

The set of sample households differed in these surveys as they were conducted with separate study objectives under different research projects. ${ }^{1}$ Most of the sampled households are from the remote islands in the Indian part of the Sundarban. The spatial coverage of the four surveys mostly includes Gram Panchayat areas in the periphery of SRF. It should be noted that in spite of the overall cross-section as well as time series characteristics, the aggregate information does not constitute a panel dataset as the primary sample units (households) were different across surveys. The set of all Gram Panchayat areas covered under these surveys is shown in Fig. 26.1.

While the survey rounds differed in their primary study objective, a common module in the survey instrument included individual member profiles including information on age, sex, educational attainment, main occupation and subsidiary occupations. These sets of individual information are rich enough to shed light on the current study objective.

\subsection{Findings}

\subsubsection{Household Size, Earning Members and Number of Activities}

The resource stress and low agricultural output per capita imply multiple supplementary earning activities taken up by household members whenever possible. Table 26.1 summarizes the findings in this regard.

\footnotetext{
1 2012: Dynamics of households' adaptation and resilience: Sundarban after cyclone Aila, sponsored by South Asian Network for Development and Environmental Economics (SANDEE).

2015: Livelihood impact of electricity and road-links in remote rural villages: a study in Sundarban delta, sponsored by National Bank for Agricultural and Rural Development (NABARD).

2017: Developmental interventions, rural transformation and environmental sustainability: A study on Sundarban in India, sponsored by Indian Council of Social Science Research (ICSSR).

2019: SAWI-Sundarbans Targeted Environmental Studies, sponsored by The World Bank.
} 


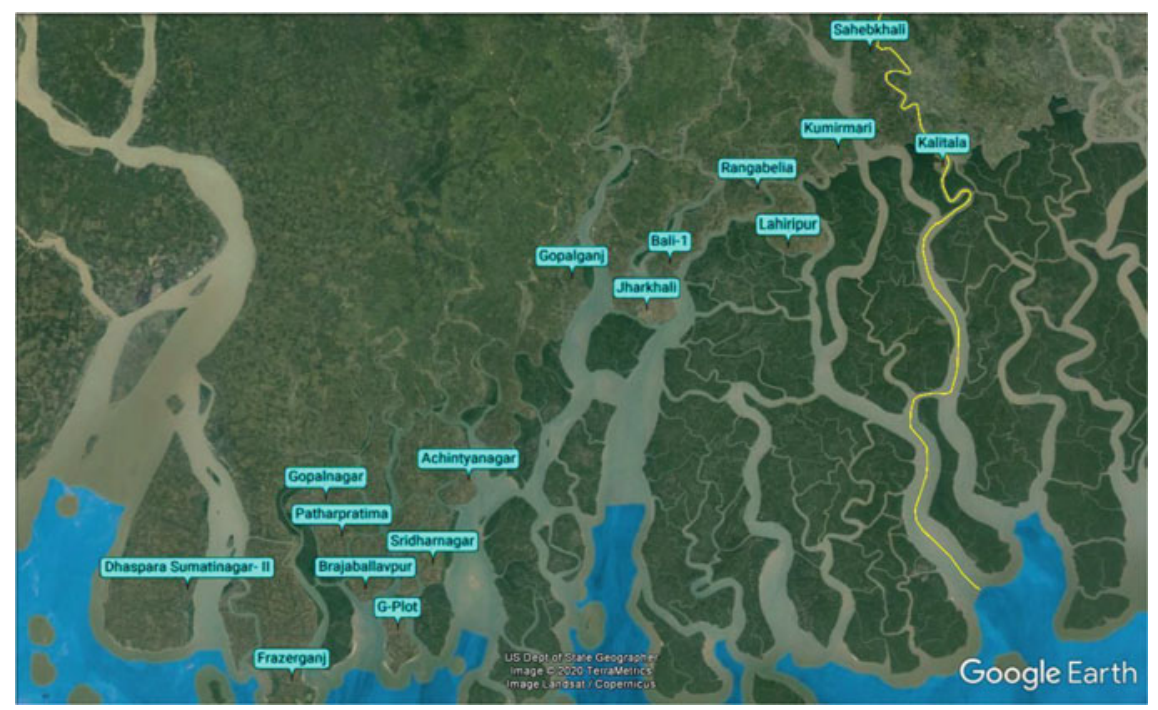

Fig. 26.1 Gram Panchayats covered for primary surveys in the Indian Sundarban. Source Google Earth

Table 26.1 Indicators for multiplicity of earning activities

\begin{tabular}{l|l|l|l|l}
\hline Indicators & $\begin{array}{l}\text { First survey } \\
(2012)\end{array}$ & $\begin{array}{l}\text { Second survey } \\
(2015)\end{array}$ & $\begin{array}{l}\text { Third survey } \\
(2017)\end{array}$ & $\begin{array}{l}\text { Fourth survey } \\
(2019)\end{array}$ \\
\hline $\begin{array}{l}\text { Average household } \\
\text { size }\end{array}$ & 4.98 & 5.45 & 4.28 & 4.47 \\
\hline $\begin{array}{l}\text { Average number of } \\
\text { earning members } \\
\text { per household }\end{array}$ & 1.91 & 1.87 & 1.72 & 2.34 \\
\hline $\begin{array}{l}\text { Average number of } \\
\text { earning activities } \\
\text { per earning member }\end{array}$ & 1.57 & 1.41 & 1.32 & 1.70 \\
\hline
\end{tabular}

Source Primary surveys in different years

The highlight of the table is the presence of more than one earning member even though the average household size is small. The earning from the primary occupation was supplemented through other activities.

Though the metrics are provided with their temporal dimension in the table, it would be wrong to conclude anything relating to their time trend. There is spatial concentration of households depending on whether their main activity is based on land or river. Hamlets located close to the rivers and the forest have a relatively larger proportion of households collecting fish and crab. Depending on the specific study objective, the selection of hamlets was done in different years with different shares of these hamlet types. It resulted in noticeable differences across columns in Table 
26.1. The main purpose of the table, however, is to provide background information on the sample households and their livelihood intensity. The main findings of this study are summarized in the following sections.

\subsubsection{The Livelihood Mix}

Information on main and subsidiary occupations across survey years were collected by aggregating all possible earning activities in the following eight mutually exclusive and exhaustive groups:

i. Agriculture and farm labour: All agriculture related activities including inland fisheries, animal husbandry and farm labour jobs.

ii. Non-farm labour: All forms of daily wage earning except from farm-sector inside Sundarban region.

iii. Fish/crab catching: All forms of collections from open rivers and forests including shrimp-seedling and honey collection.

iv. Migrant labour: All labour jobs taken up in locations outside Sundarban region.

v. Self-employed professional: All specialized commercial activities requiring skills like private tuition, traditional medicine (quacks), priests etc.

vi. Business: Any other commercial enterprise requiring capital investment.

vii. Salaried employment: Regular employment, mostly teachers and staffs in local primary schools, government enrolled village health workers, other staff at local Panchayat office, NGO-workers with regular salary, etc.

viii. Other Miscellaneous: Rent earning, old-age pension, widow pension, disability pension, etc.

Since earning members generally show a multitude of earning activities, it is difficult to identify each of them exclusively with one of the above categories. Hence, all the earning members in different survey rounds are categorized following their self-reported 'primary' occupation only. Figure 26.2 describes the relative share of these occupations over survey years.

The relative shares of activities vary across the survey rounds due to differential choice of hamlets, as described before. But the robustness of finding lies with the consistent high rank of the three livelihood options across the years-agriculture, fishing and migrant labour jobs. The predominance of these three activities, in spite of differences in sample hamlets, endorses the postulate regarding limitation of livelihood options in the delta. 


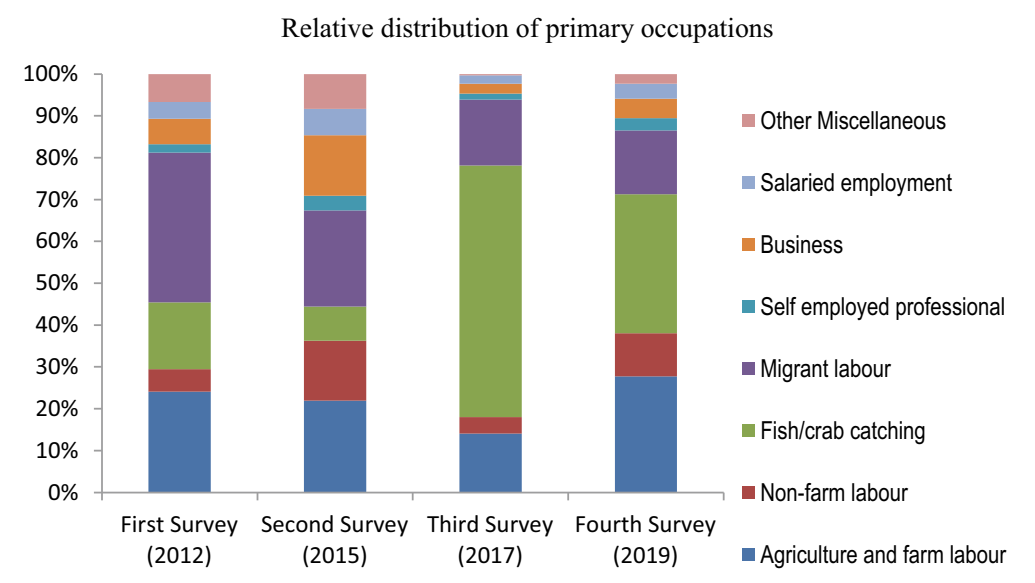

Fig. 26.2 Relative distribution of primary occupations. Source Primary survey

\subsubsection{Livelihood Across Age and Education}

It is interesting to see how these livelihood options are distributed among earning adults when they are categorized across age groups. In the aggregate dataset, age of an earning member showed a range of 10-96 years. Age below 15 years was recorded only for a few members engaged in shrimp juvenile collection. A couple of very old (more than 90 years) earning members were also found who were 'earning' as recipients of old-age pension.

Figure 26.3 describes the average age of earning members across the eight activities over the survey rounds. The figure clearly indicates that migrant labour jobs involve the youngest of the labour force from the delta. The robustness of this observation is also revealed by the figure as this phenomenon is markedly similar across all survey years.

A marked difference in average age across occupations is indicative of the inherent livelihood dynamics across generations. In the beginning, islanders started with agriculture as their main occupation. Gradually people resorted more to fish/crab collection, and later, migrant labour jobs have been replacing both of these activities for the younger generation. The gradual lowering of the height of the bars across these three activities might be interpreted in this light. The average age for 'other miscellaneous' activities is always much higher as it consists of old-age and widow pensioners. All other occupation choices show more or less similar values for their average age, which is also close to the overall average in the sample.

The educational status, indicating the human capital one possesses, is another interesting aspect to look at. For easier understanding, information on individual educational attainments is categorized into four mutually exclusive and exhaustive classes. The overall education profile of the earning members in the sample is shown in Fig. 26.4, which describes the relative shares of the four education classes. It 


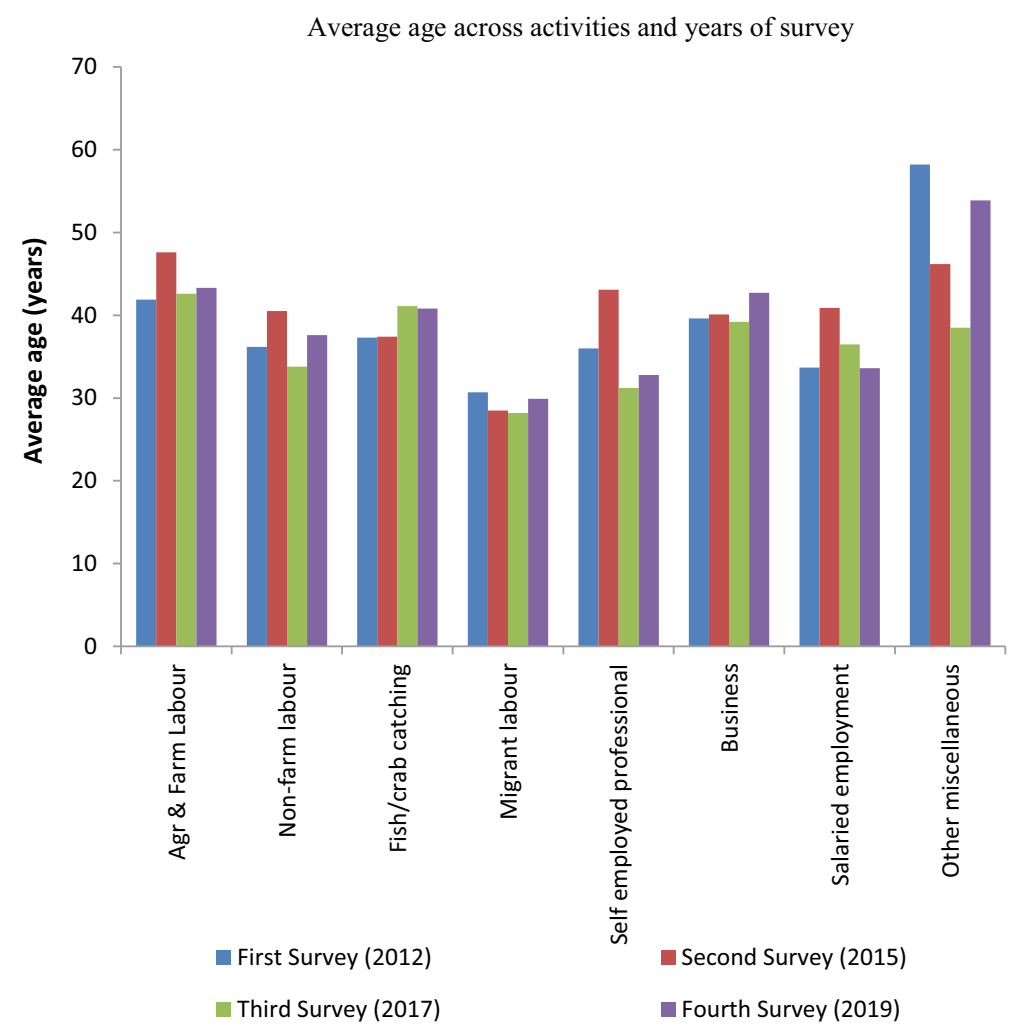

Fig. 26.3 Average age across activities and years of survey. Source Primary survey

Educational attainments of earning adults

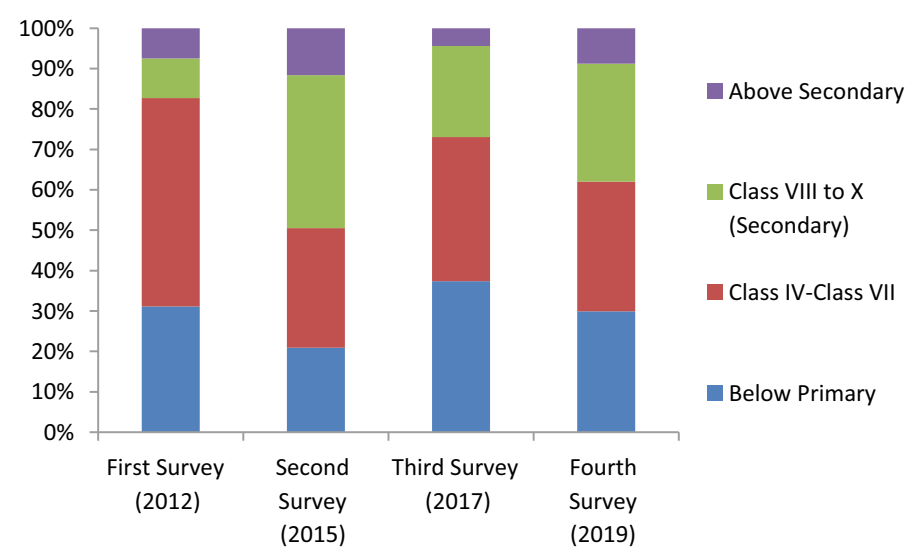

Fig. 26.4 Educational attainments of earning adults. Source Primary survey 


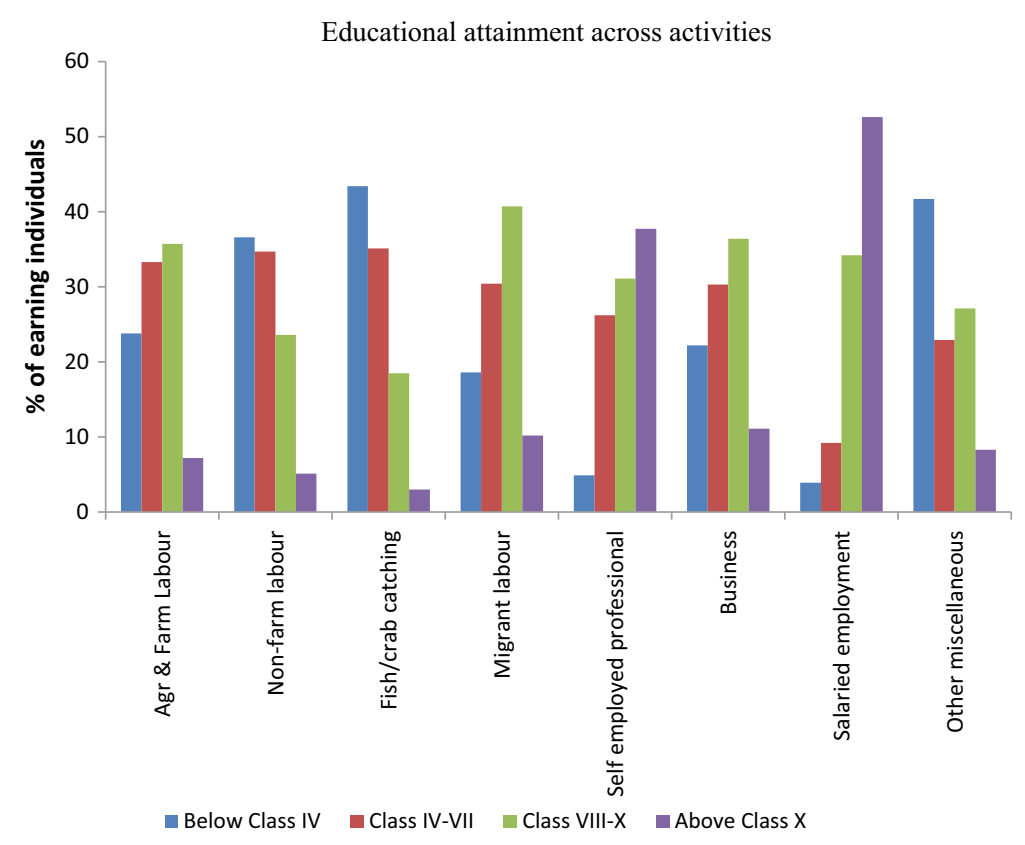

Fig. 26.5 Educational attainment across activities. Source Survey in 2019

is clear that the earning adults in the delta are poorly educated, with only a small fraction of them being able to proceed beyond the secondary level.

Further education-activity decomposition gives more interesting insights. To keep the information simple and easy to comprehend, Fig. 26.5 is produced using only the latest survey year (2019). The figure, however, captures the essence of the distribution, which is found to be robust across other survey years as well.

It is observed that the lowest education class (below class IV) forms the modal class for 'Non-farm labourers' and 'Fish/crab catchers'. It is also the modal class for old people earning from old-age and widow pensions (other miscellaneous), who constitute the bulk of the local illiterate population. The spread of more accessible primary and secondary education in these remote islands is a relatively recent phenomenon.

The study finds that only a negligible section of the local people could reach up to graduation level. The majority of these graduates are found to be engaged in private tuition (self-employed professional) and a handful of them could become teachers in local primary schools (salaried employment). This explains the dominance of the highest educational class for these activities.

The most interesting aspect in Fig. 26.5 is the completely opposite educational attainment pattern between 'fish/crab catchers' and 'migrant labourers'. The former category is heavily skewed towards the lowest education class while it is just the opposite for the migrants. 


\subsection{Conclusions and Policy Implications}

The Sundarban is a very important geographical region both for the ecological health of the Bay of Bengal and the millions of poor people in Bangladesh and India that inhabit the area. Its geographical and ecological aspects have been studied over the last several decades. The region caught the fancy of the research community with climate change-related vulnerabilities identified for its large resident population. On the Indian side, the region is also witness to significant dynamics in livelihood owing to availability of mobile communication and transport infrastructure in recent years. Yet, studies on these livelihood dynamics supported by micro-level data are scarce in the literature.

This study bridges this crucial research gap by using information from several rounds of household surveys that were conducted in the Indian part of the Sundarban over the last decade. The majority of the sample observations belong to the peripheral hamlets of Sundarban Reserve Forest. The pooled data of 2800 households and over 5500 adult earning members unfolds an interesting story of people's resilience in the face of climate change-induced loss in their traditional livelihood. The study finds strong empirical evidence suggesting that the younger generation in the delta is coping with the situation by moving out of the region as migrant labour. Such livelihood dynamics might be considered ecologically beneficial as it reduces the anthropogenic stress on the mangrove ecosystem.

The study also finds that a little improvement in individual educational attainments can cause an increase in this labour outflow. A strong positive inducement for this is found to exist for education up to secondary level. Working at a distant location and in a completely different cultural environment might need a level of communication and information gathering skill that the illiterate or very minimally educated people do not possess. This finding has important policy implications. Additional government initiatives in enhancing school enrolment, arresting school dropouts and incentivizing educational attainments up to secondary level can be a policy handle for an ecological goal. It seems that enhancing the basic educational infrastructure in this remote deltaic region goes much beyond its apparent objective of building social capital in general. In an ecological hotspot like the Sundarban, such investments in education would increase community resilience in the face of climate change threats to their traditional livelihood.

\subsection{Limitations and Scope for Further Research}

This study is intended to shed light on the dynamics of livelihood mix in Indian Sundarban and its implication for local ecology. The empirical estimates reported here should be interpreted with a word of caution. The region is characterized by spatial concentration of fish/crab-based livelihood in the proximity of rivers. For villages or hamlets away from rivers, livelihood is mostly based on agriculture. 
The proportion of households depending directly on natural resources would vary depending on the choice of sample hamlets. In this study, hamlet selections were not purely random, and hence, the overall sample might not be directly used for population estimates on livelihood mix. However, this study is not attempting to make any such estimation either. It might be noted that households were selected as stratified random samples from within those hamlets, where stratification was done on the basis of landholding. Deeper investigations on the factors inducing the youth for migrating out, and the marginal effect of such outmigration on local ecological indicators remains an interesting and open research agenda for Sundarban.

Acknowledgements This paper is based on data pooled from four different studies in Indian Sundarban over the decade of 2010-2020. The authors sincerely acknowledge the sponsors of all these studies which include South Asian Network for Development and Environmental Economics (SANDEE, Kathmandu); Department of Economic Analysis and Research, National Bank for Agricultural and Rural Development (DEAR, NABARD, Mumbai); Indian Council of Social Science Research (ICSSR, New Delhi) and the World Bank (Washington, DC). The authors, however, are solely responsible for the conclusions and any possible errors in this study.

\section{References}

Banerjee, K. (2013). Decadal change in the surface water salinity profile of Indian sundarbans: A potential indicator of climate change. Journal of Marine Science: Research \& Development, 01(S11). https://doi.org/10.4172/2155-9910.S11-002

Chand, B. K., Trivedi, R. K., Biswas, A., Dubey, S. K., \& Beg, M. M. (2012). Study on impact of saline water inundation on freshwater aquaculture in Sundarban using risk analysis tools. Exploratory Animal and Medical Research, 2, 170-178.

Chowdhury, A., Sanyal, P., \& Maiti, S. K. (2016). Dynamics of mangrove diversity influenced by climate change and consequent accelerated sea level rise at Indian Sundarbans. International Journal of Global Warming, 9(4), 486. https://doi.org/10.1504/IJGW.2016.076333

Das, C. S. (2018). Pattern and characterisation of human casualties in Sundarban by Tiger attacks, India. Sustainable Forestry, 1(4). https://doi.org/10.24294/sf.v1i2.873

Das, S. (2021). Valuing the role of mangroves in storm damage reduction in coastal areas of Odisha. In A. K. E. Haque, P. Mukhopadhyay, M. Nepal \& M. R. Shammin (Eds.), Climate change and community resilience: Insights from South Asia (pp. 257-273). Springer Nature.

Dasgupta, S. (2017). The impact of aquatic salinization on fish habitats and poor communities in a changing climate: Evidence from Southwest Coastal Bangladesh. Ecological Economics, 12.

Dasgupta, S., Hossain, Md. M., Huq, M., \& Wheeler, D. (2018). Climate change, salinization and high-yield rice production in coastal Bangladesh. Agricultural and Resource Economics Review, 47(1), 66-89. https://doi.org/10.1017/age.2017.14

Dasgupta, S., Sobhan, I., \& Wheeler, D. (2017). The impact of climate change and aquatic salinization on mangrove species in the Bangladesh Sundarbans. Ambio, 46(6), 680-694.

Dasgupta, S., Wheeler, D., Sobhan, M. I., Bandyopadhyay, S., Nishat, A., \& Paul, T. (2020). Coping with the vulnerability of the sundarban in a changing climate: Lessons from multidisciplinary studies. World Bank. https://openknowledge.worldbank.org/handle/10986/34770

Dutta, S., Chakraborty, K., \& Hazra, S. (2017). Ecosystem structure and trophic dynamics of an exploited ecosystem of Bay of Bengal, Sundarban Estuary, India. Fisheries Science, 83(2), 145-159. https://doi.org/10.1007/s12562-016-1060-2 
Ghosh, S. (2013). Extreme event, anthropogenic stress and ecological sustainability in Sundarban Islands. Vidyasagar University Journal of Economics, XVII, 132-148.

Ghosh, S. (2017). Coping with a natural disaster: Sundarbans after Cyclone Aila. In Global change, ecosystems, sustainability: Theory, methods, practice (pp. 116-136). SAGE Publications, Inc.

Gopal, B., \& Chauhan, M. (2006). Biodiversity and its conservation in the Sundarban Mangrove ecosystem. Aquatic Sciences, 68(3), 338-354. https://doi.org/10.1007/s00027-006-0868-8

Guha, I., \& Roy, C. (2016). Climate change, migration and food security: Evidence from Indian Sundarbans. International Journal of Theoretical and Applied Sciences, 8(2), 45-49.

Hajra, R., \& Ghosh, T. (2018). Agricultural productivity, household poverty and migration in the Indian Sundarban Delta. Elementa: Science of the Anthropocene, 6(1).

Haldar, A., \& Debnath, A. (2014). Assessment of climate induced soil salinity conditions of Gosaba Island, West Bengal and Its Influence on Local Livelihood. In M. Singh, R. B. Singh, \& M. I. Hassan (Eds.), Climate change and biodiversity (pp. 27-44). Springer Japan. https://doi.org/10. 1007/978-4-431-54838-6_3

Hoq, M. E. (2007). An analysis of fisheries exploitation and management practices in Sundarbans mangrove ecosystem, Bangladesh. Ocean \& Coastal Management, 50(5), 411-427. https://doi. org/10.1016/j.ocecoaman.2006.11.001

Hoque Mozumder, M. M., Shamsuzzaman, Md. M., Rashed-Un-Nabi, Md., \& Karim, E. (2018). Social-ecological dynamics of the small scale fisheries in Sundarban Mangrove Forest, Bangladesh. Aquaculture and Fisheries, 3(1), 38-49. https://doi.org/10.1016/j.aaf.2017.12.002

Islam, S. (2014). An analysis of the damages of Chakoria Sundarban mangrove wetlands and consequences on community livelihoods in south east coast of Bangladesh. International Journal of Environment and Sustainable Development, 13, 153-171. https://doi.org/10.1504/IJESD.2014. 060196

Mahadevia Ghimire, K., \& Vikas, M. (2012). Climate change-Impact on the Sundarbans: A case study. International Scientific Journal, 2, 7-15.

Mishra, A. (2014). Temperature rise and trend of cyclones over the Eastern Coastal Region of India. Journal of Earth Science and Climatic Change, 05(09). https://doi.org/10.4172/2157-7617.100 0227

Mistri, A. (2013). Migration and sustainable livelihoods: A study from Sundarban biosphere reserve. Asia Pacific Journal of Social Sciences, 5(2), 76-102.

Mistri, A., \& Das, B. (2015). Environmental legislations and livelihood conflicts of Fishermen in Sundarban, India. Asian Profile, 43, 389-400.

Mondal, M., Islam, M., Islam, M., Barua, S., Hossen, S., Ali, M., \& Hossain, M. B. (2018). Pearson's correlation and likert scale based investigation on livelihood status of the Fishermen living around the Sundarban Estuaries, Bangladesh. Middle East Journal of Scientific Research, 26. https://doi. org/10.5829/idosi.mejsr.2018.182.190

Nandi, N., \& Pramanik, S. (2017). Livelihood on Mud Crab catchment: A case study of Sundarban Coast, West Bengal, India (Vol. 1). https://doi.org/10.29011/2577-1493.100003

Neogi, S. B., Dey, M., Kabir, S. L., Masum, S. J. H., Kopprio, G., Yamasaki, S., \& Lara, R. (2017). Sundarban mangroves: Diversity, ecosystem services and climate change impacts. Asian Journal of Medical and Biological Research, 2(4), 488-507. https://doi.org/10.3329/ajmbr.v2i4.30988

Raha, A., Das, S., Banerjee, K., \& Mitra, A. (2012). Climate change impacts on Indian Sunderbans: A time series analysis (1924-2008). Biodiversity and Conservation, 21(5), 1289-1307. https:// doi.org/10.1007/s10531-012-0260-Z

Smith, T. J., Boto, K. G., Frusher, S. D., \& Giddins, R. L. (1991). Keystone species and mangrove forest dynamics: The influence of burrowing by crabs on soil nutrient status and forest productivity. Estuarine, Coastal and Shelf Science, 33(5), 419-432. https://doi.org/10.1016/0272-7714(91)900 $81-\mathrm{L}$ 
World Bank, W. (2014). Building resilience for sustainable development of the Sundarbans: Strategy report (No. 20116; World Bank Other Operational Studies). The World Bank. https://ideas.repec. org/p/wbk/wboper/20116.html

World Wildlife Fund. (n.d.). About Sundarbans. WWF India. https://www.wwfindia.org/about_ wwf/critical_regions/sundarbans3/about_sundarbans/. Last accessed December 26, 2020.

Open Access This chapter is licensed under the terms of the Creative Commons AttributionNonCommercial-NoDerivatives 4.0 International License (http://creativecommons.org/licenses/bync-nd/4.0/), which permits any noncommercial use, sharing, distribution and reproduction in any medium or format, as long as you give appropriate credit to the original author(s) and the source, provide a link to the Creative Commons licence and indicate if you modified the licensed material. You do not have permission under this licence to share adapted material derived from this chapter or parts of it.

The images or other third party material in this chapter are included in the chapter's Creative Commons licence, unless indicated otherwise in a credit line to the material. If material is not included in the chapter's Creative Commons licence and your intended use is not permitted by statutory regulation or exceeds the permitted use, you will need to obtain permission directly from the copyright holder.

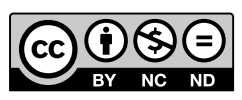

